\title{
shRNAs targeting high-mobility group box-1 inhibit E-selectin expression via homeobox A9 in human umbilical vein endothelial cells
}

\author{
XIAO-JUAN ZHANG, ZHENG-GANG LUAN and XIAO-CHUN MA \\ Intensive Care Unit, First Affiliated Hospital of China Medical University, Shenyang, Liaoning 110001, P.R. China
}

Received October 23, 2012; Accepted January 30, 2013

DOI: $10.3892 / \mathrm{mmr} .2013 .1314$

\begin{abstract}
The nucleus of the endothelial cell contains large amounts of high-mobility group box protein 1 (HMGB1), a cytokine mediator of inflammation, and the endothelium may be a crucial source of HMGB1 during the inflammatory response. Therefore, the downregulation of HMGB1 expression by RNA interference (RNAi) may decrease inflammatory activity. The aim of this study was to investigate the possible mechanism of action and the effect of HMGB1 on homeobox A9 (HOXA9) and E-selectin expression. Recombinant human full-length HMGB1 was cloned by PCR amplification from human umbilical vein endothelial cells (HUVECs) and then subcloned into a pcDNA-3.1-myc-his-B vector. Specific short hairpin RNAs (shRNAs) for the HMGB1 target sequence and a scrambled sequence were designed, synthesized and cloned into a pRNA-U6.1/Neo vector. Specific small interfering RNAs (siRNAs) for the HOXA9 target sequence were commercially prepared and the expression levels of HMGB1, HOXA9, intracellular adhesion molecule 1 (ICAM1), vascular cell adhesion molecule 1 (VCAM1) and E-selectin were detected using real-time PCR and western blot analysis. The expression of the full-length HMGB1 gene and protein was verified in HUVECs. The shRNA for HMGB1 and siRNA for HOXA9
\end{abstract}

Correspondence to: Dr Xiao-Chun Ma, Intensive Care Unit, First Affiliated Hospital of China Medical University, 92 Bei-er Road, Shenyang, Liaoning 110001, P.R. China

E-mail: zxj950122@sina.com

Abbreviations: FBS, fetal bovine serum; GAPDH, glyceraldehyde 3-phosphate dehydrogenase; HMGB1, high-mobility group box protein 1; HMGI(Y), high-mobility group AT-hook 1; HOXA9, homeobox A9; HUVEC, human umbilical vein endothelial cell; ICAM1, intracellular adhesion molecule 1; IL, interleukin; LPS, lipopolysaccharide; MOF, multiple organ failure; NF- $\mathrm{B}$, nuclear factor $\kappa$-light-chain-enhancer of activated B cells; RNAi, RNA interference; siRNA, small interfering RNA; shRNA, short hairpin RNA; TNF, tumor necrosis factor; VCAM1, vascular cell adhesion molecule 1

Key words: high-mobility group 1, human umbilical vein endothelial cells, homeobox A9, E-selectin, sepsis successfully decreased the expression levels of HMGB1 and HOXA9, respectively. ICAM1, VCAM1 and E-selectin were downregulated through HMGB1 interference in HUVECs, and HMGB1 shRNA decreased E-selectin expression by HOXA9. These results demonstrated the potential use of specific siRNA targeting HMGB1 expression for the development of novel therapeutic agents for inflammatory disorders.

\section{Introduction}

High-mobility group box protein 1 (HMGB1) is a nuclear protein present in all mammals and conserved across species. HMGB1 appears to have two distinct functions in cells. The main intranuclear function of HMGB1 is to regulate transcription and modify chromatin structure (1-3). Extracellular HMGB1 stimulates the secretion of proinflammatory cytokines from endothelial cells, monocytes and macrophages, leading to inflammatory responses in target tissues $(4,5)$.

Previous studies have demonstrated that extracellular HMGB1 is a late cytokine mediator of delayed endotoxin lethality $(6,7)$. HMGB1 has been detected in the serum of patients with sepsis, and serum HMGB1 levels are significantly elevated in patients with poor prognoses. However, the mechanism by which intracellular HMGB1 participates in inflammation remains unclear.

Despite the use of antibiotics and modern intensive care, severe sepsis has a mortality rate of $\sim 30 \%$, resulting in an estimated 250,000 deaths annually in the United States (8). Microvascular injury is one of the characteristics of sepsis-associated tissue damage, and may be manifested by single or multiple organ failure (MOF) syndromes (9).

The endothelium plays an important role in the development of sepsis. The nucleus of the endothelial cell contains large amounts of HMGB1. A number of studies have demonstrated that the endothelium may be a critical source of HMGB1 in inflammation $(10,11)$. In a clinically relevant murine model of sepsis (induced by cecal ligation and puncture), administration of HMGB1-specific neutralizing antibodies $24 \mathrm{~h}$ after the onset of sepsis rescued mice from lethal sepsis in a dose-dependent manner $(12,13)$. This indicates that further investigation of the function of HMGB1 in inflammation may be important for the improvement of the treatment of inflammatory diseases, particularly sepsis. 
Based on the HMGB1-specific antibody results in sepsis, we hypothesized that the downregulation of HMGB1 expression via RNA interference (RNAi) decreases inflammatory activity. Vectors capable of producing short hairpin RNAs (shRNAs), which are processed to form small interfering RNAs (siRNAs), enable the suppression of endogenous gene expression $(14,15)$. A previous study demonstrated the potential of chemically synthesized antisense oligonucleotides targeting HMGB1 expression to significantly inhibit colon cancer cell growth, migration and invasion (16). However, the gene-silencing effects of HMGB1 RNAi on endothelial cell function remain unknown.

Increased expression levels of endothelial adhesion molecules, either at the membrane level or in the plasma, characterize the different models of sepsis (17). In vitro incubation of endothelial cells with bacterial lipopolysaccharide (LPS) has been shown to induce the rapid expression of intracellular adhesion molecule 1 (ICAM1) and E-selectin mRNA (18). Moreover, there is a close relationship between plasma levels of adhesion molecules and the consequences of sepsis (19). In various models of sepsis, endothelial adhesion molecules were found to be present at elevated levels in membranes and plasma. Previous studies have identified HOXA9 to be a key regulator of endothelial activation (20). HOXA9 also participates in the transcriptional activation of E-selectin in endothelial cells (21).

In the present study, a stable, HMGB1-silencing human umbilical vein endothelial cell (HUVEC) line was established using RNAi technology and eukaryotic expression vectors carrying the full-length cDNA of HMGB1 (pcDNA3.1-myc-his-HMGB1) were constructed. The effects of subsequent HMGB1 knockdown on HOXA9, E-selectin, ICAM1 and vascular cell adhesion molecule 1 (VCAM1) expression were then evaluated. The potential mechanism by which the HMGB1 gene affects endothelial cell activation was investigated.

\section{Materials and methods}

Cells. HUVECs (CRL-2873; American Type Culture Collection, Mannassas, VA, USA) were maintained in Dulbecco's modified Eagle's medium (DMEM) and supplemented with $10 \%$ fetal bovine serum (FBS; HyClone Laboratories, Inc., Logan, UT, USA), 2 mM glutamine, $100 \mathrm{IU} / \mathrm{ml}$ penicillin and $100 \mathrm{mg} / \mathrm{ml}$ streptomycin. The cells were incubated at $37^{\circ} \mathrm{C}$ in a $5 \% \mathrm{CO}_{2} / 95 \%$ air-humidified atmosphere.

Western blot analysis. The cells were washed twice with ice-cold phosphate-buffered saline (PBS) and prepared with radioimmunoprecipitation assay lysis buffer $(50 \mathrm{mM}$ Tris- $\mathrm{HCl}$, $150 \mathrm{mM} \mathrm{NaCl}, 1 \%$ Nonidet P-40, $0.5 \%$ deoxycholate and $0.1 \%$ sodium dodecyl sulfate) containing a protease inhibitor mixture (Roche, Basel, Switzerland). The samples were separated by sodium dodecyl sulfate-polyacrylamide gel electrophoresis and then transferred to polyvinylidene difluoride membranes (Millipore, Billerica, MA, USA) using a SemiDry Transfer Cell (Bio-Rad, Hercules, CA, USA). Polyvinylidene difluoride membranes were blocked with $5 \%$ nonfat milk and incubated with the first antibody at $4^{\circ} \mathrm{C}$ overnight. The blots were then incubated with a horseradish peroxidase-conjugated secondary antibody (Santa Cruz Biotechnology, Inc., Santa Cruz, CA, USA) for $1 \mathrm{~h}$ at room temperature.

Immunoreactive bands were visualized using the SuperSignal West Pico Chemiluminescent Substrate (Pierce, Rockford, IL, USA) and LAS-3000 mini (Fuji Film, Fuji, Japan). The antibodies against HMGB1, ICAM1, VCAM1, E-selectin and glyceraldehyde 3-phosphate dehydrogenase (GAPDH) were obtained from Abcam (cat. nos. ab18256, ab19569, ab2213 and ab6630; Cambridge, UK) and Santa Cruz Biotechnology, Inc., respectively.

Plasmid construction and transfection. The full-length HMGB1 (GenBank accession no. NM_002128) cDNA was obtained by reverse transcription (RT)-PCR from HUVECs and cloned into pcDNA3.1/myc-his-B (Invitrogen, Carlsbad, CA, USA) using KpnI and $E c o$ RI. The primers for the full-length HMGB1 were: forward, ATGGGCAAAGGAGATCCTAAGA and reverse, TTCATCATCATCATCTTCTTC. All the cDNAs were analyzed by DNA sequencing to ensure that there were no mutations. HUVECs were transfected with the constructed plasmids using Lipofectamine ${ }^{\mathrm{TM}} 2000$ (Invitrogen), and the expression of HMGB1 was verified by western blot analysis.

$R N A i$. The siRNA for a sequence targeting human HMGB1 to the coding regions, 5'-AAGGTTGAGAGC TATTGCTGA-3', was constructed using the siRNA design center from GenScript (GenScript, Piscataway, NJ, USA). A non-silencing, scrambled siRNA sequence (5'-TTCTCCGAACGTGTCACGT-3') was used as a control. The siRNA sequence was inserted into the pRNA-U6.1/Neo vector (GenScript), recombinant siRNA plasmids were transfected into HUVECs, and stable transfectants were selected with G418.

Transfection. HUVECs in which HMGB1 was silenced were transfected with the siRNAs targeted to HOXA9 using Lipofectamine $^{\mathrm{TM}} 2000$ according to the manufacturer's instructions. The mRNA and protein expression levels of HMGB1 and HOXA9 were determined using real-time PCR and western blot analysis, respectively.

Real-time PCR. Total RNA was treated with RNase-free DNase I (Takara Bio, Tokyo, Japan) and reverse transcribed with Avian Myeloblastosis Virus Reverse Transcriptase (Promega, Madison, WI, USA). Real-time PCR was performed using an ABI 7500 real-time PCR system (Applied Biosystems, Foster City, CA, USA) with an Ex Taq RT-PCR kit (Takara Bio), according to the manufacturer's instructions. The sequences of primers for human HMGB1, HOXA9, ICAM1, VCAM1, E-selectin and GAPDH are shown in Table I. Amplification conditions were: $95^{\circ} \mathrm{C}$ for $10 \mathrm{sec}, 40$ cycles of $95^{\circ} \mathrm{C}$ for $5 \mathrm{sec}$, and $64^{\circ} \mathrm{C}$ for $34 \mathrm{sec}$. The quantities of HMGB1, HOXA9, ICAM1, VCAM1 and E-selectin transcripts for individual samples were normalized to GAPDH.

Statistical analysis. Data analysis was conducted using SPSS 17.0 software. Data were expressed as the means \pm standard deviation (SD). Statistical analysis between groups was performed using Student's t-test and ANOVA. P $<0.05$ was considered to indicate a statistically significant difference. 
Table I. Primers for real-time PCR.

\begin{tabular}{|c|c|c|c|}
\hline Target & Amplicon length (bp) & Oligonucleotide sequence & GenBank accession no. \\
\hline HMGB1 & 186 & $\begin{array}{l}\text { F:GGGGTACCATGGGCAAAGGAGATCCTAAGA } \\
\text { R: CGGAATTCGTTTCATCATCATCATCTTCTTC }\end{array}$ & NM_002128 \\
\hline HOXA9 & 152 & $\begin{array}{l}\text { F: TACGTGGACTCGTTCCTGCT } \\
\text { R: CGTCGCCTTGGACTGGAAG }\end{array}$ & NM_152739.3 \\
\hline ICAM1 & 112 & $\begin{array}{l}\text { F: ATGCCCAGACATCTGTGTCC } \\
\text { R: GGGGTCTCTATGCCCAACAA }\end{array}$ & NM_000201 \\
\hline VCAM1 & 60 & $\begin{array}{l}\text { F: CGAATGAGGGGACCACATCTA } \\
\text { R: TGTTCGTTCCCAAAACTAACAGG }\end{array}$ & NM_080682 \\
\hline E-selectin & 185 & $\begin{array}{l}\text { F: TGTGGGTCTGGGTAGGAACC } \\
\text { R: AGCTGTGTAGCATAGGGCAAG }\end{array}$ & NM_000450 \\
\hline GAPDH & 225 & $\begin{array}{l}\text { F: GAAGGTGAAGGTCGGAGTC } \\
\text { R: CAAGCTTCCCGTTCTCAGCC }\end{array}$ & NM_002046 \\
\hline
\end{tabular}

HMGB1, high-mobility group box protein 1; HOXA9, homeobox A9; ICAM1, intracellular adhesion molecule 1; VCAM1, vascular cell adhesion molecule 1; GAPDH, glyceraldehyde 3-phosphate dehydrogenase; F, forward; R, reverse.

\section{Results}

Effects of shRNA-mediated suppression of HMGBI expression in HUVECs. To explore the role of HMGB1 in HUVECs, the siRNA technique was used to knockdown HMGB1 expression. Specific siRNA targeting HMGB1 was designed and the double-stranded siRNA was inserted into pRNA-U6.1/Neo siRNA vector, with scrambled, non-silencing siRNA as a control. siRNA constructs were stably transfected into HUVECs and the silencing effect was determined using real-time PCR and western blot analysis. The results showed that HMGB1 siRNA was efficient in suppressing the expression of HMGB1 in HUVECs compared with the non-silencing siRNA control at the mRNA (Fig. 1A) and protein (Fig. 1B) levels.

HMGB1 knockdown decreases E-selectin expression in HUVECs. Cell adhesion molecules (CAMs) such as VCAM1, ICAM1 and E-selectin are involved in the inflammatory process (22). Inhibitors of cell adhesion molecules may be useful therapeutic agents for vascular diseases including atherosclerosis (23). To explore the function of HMGB1 in inflammation, we detected the expression of VCAM1, ICAM1 and E-selectin in HMGB1-silenced HUVECs. The results showed that the expression levels of VCAM1, ICAM1 and E-selectin were significantly decreased in HUVECs transfected with HMGB1-specific siRNA compared with those in control cells, at the mRNA (Fig. 2A) and protein (Fig. 2B and C) levels.

Role of HOXA9 in the regulation of E-selectin expression. HOXA9 is a homeobox transcription factor and is rapidly downregulated during endothelial cell activation in response to tumor necrosis factor (TNF)- $\alpha$ (24). HOXA9 downregulation is considered an essential event for endothelial cell activation. Previous studies have demonstrated that TNF- $\alpha$ and LPS activate endothelial cells by inducing the expression of leukocyte
A

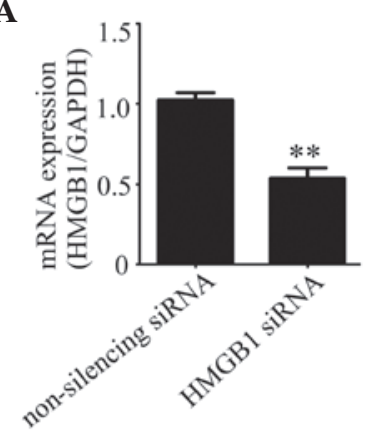

B

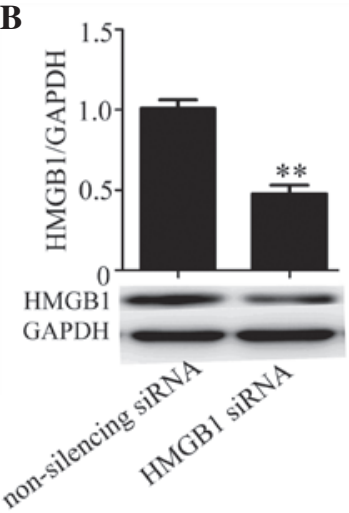

Figure 1. Construction of stable HMGB1-silenced cells. HUVECs were stably transfected with HMGB1 siRNA or non-silencing siRNA, and HMGB1 expression was detected by (A) real-time PCR and (B) western blot analysis. Values are the means \pm SD of three independent experiments, each performed in triplicate. ${ }^{* *} \mathrm{P}<0.01$ vs. non-silencing siRNA. HMGB1, high-mobility group box protein 1; HUVECs, human umbilical vein endothelial cells; siRNA, small interfering RNA; GAPDH, glyceraldehyde 3-phosphate dehydrogenase.

adhesion molecules such as ICAM1, VCAM1 and E-selectin, which are not expressed by quiescent endothelial cells (25). Trivedi et al (21) demonstrated that TNF- $\alpha$ and LPS downregulate HOXA9, which is an essential event for the transition of endothelial cells from a quiescent to an active state.

To explore the effects of HMGB1 silencing in HUVECs on the expression of adhesion molecules, siRNA was used to knockdown the expression of HOXA9 in HUVECs in which HMGB1 expression was silenced. After transfection with Lipofectamine ${ }^{\mathrm{TM}} 2000$ for $48 \mathrm{~h}$, the gene-silencing effect mediated by HOXA9-specific siRNAs in HUVECs was confirmed using RT-PCR and western blot analysis. The expression of E-selectin was measured using real-time PCR. The results showed that HOXA9 siRNA was efficient in suppressing the expression of HOXA9 in HUVECs compared 
A

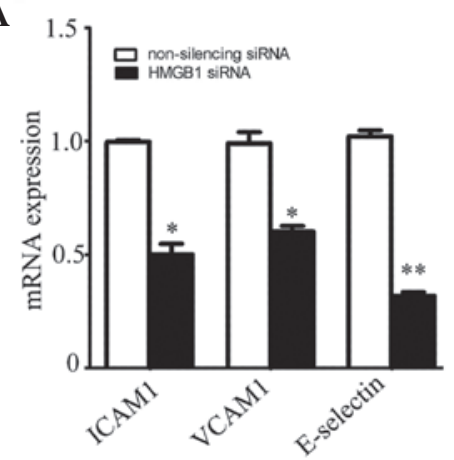

B

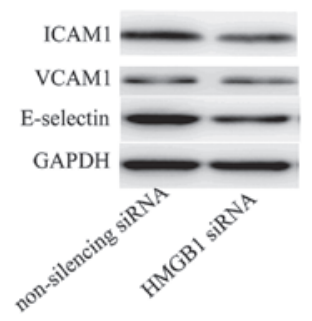

C

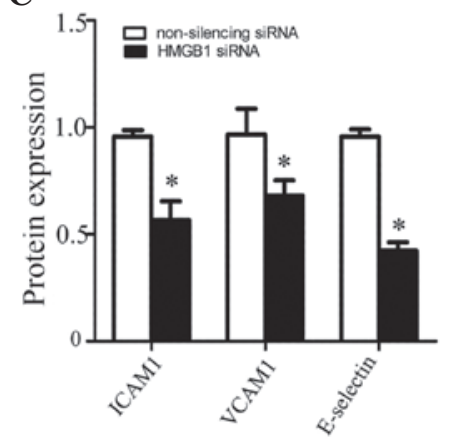

Figure 2. Expression of cell adhesion molecules in HMGB1-silenced HUVECs. The expression of VCAM1, ICAM1 and E-selectin in HUVECs transfected with HMGB1 siRNA or non-silencing siRNA was detected by (A) real-time PCR and (B) western blot analysis. VCAM1, ICAM1, E-selectin and GAPDH protein bands $(\mathrm{C})$ were measured using Image $\mathbf{J}$ software. Values are the means $\pm \mathrm{SD}$ of three independent experiments, each performed in triplicate. "P $<0.05$, ${ }^{* *} \mathrm{P} \leq 0.01$ vs. non-silencing siRNA. HMGB1, high-mobility group box protein 1 ; HUVECs, human umbilical vein endothelial cells; VCAM1, vascular cell adhesion molecule 1; ICAM1, intracellular adhesion molecule 1; siRNA, small interfering RNA; GAPDH, glyceraldehyde 3-phosphate dehydrogenase.

A

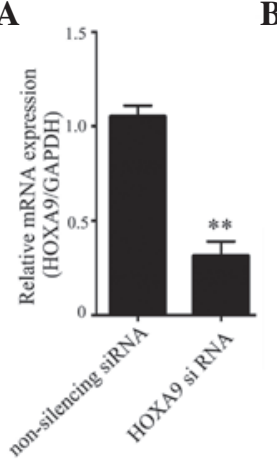

B

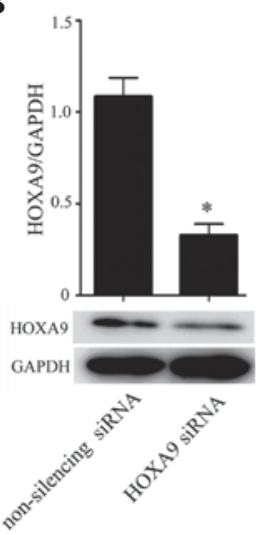

C

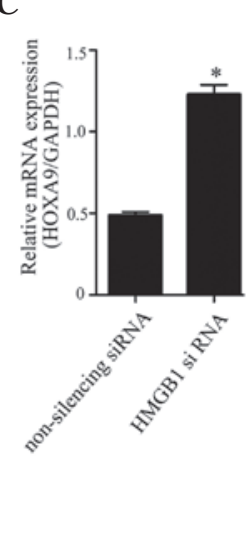

$\mathbf{D}$

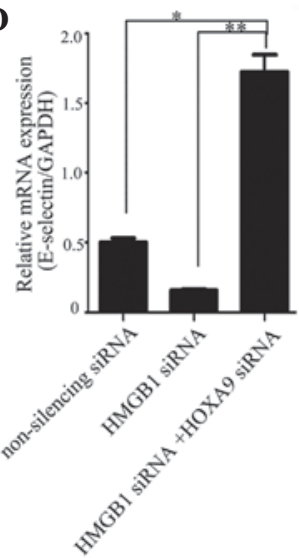

Figure 3. E-selectin expression is regulated by HOXA9 in HUVECs. HMGB1-silenced cells were transiently transfected with HOXA9 siRNA or non-silencing siRNA, and HOXA9 expression was detected by (A) real-time PCR and (B) western blot analysis. (C) The expression of HOXA9 in HMGB1-silenced cells was detected by real-time PCR and (D) the expression of E-selectin was measured by real-time PCR. Values are the means \pm SD of three independent experiments, each performed in triplicate. ${ }^{*} \mathrm{P}<0.05,{ }^{* *} \mathrm{P} \leq 0.01$ vs. non-silencing siRNA. HOXA9, homeobox A9; HUVECs, human umbilical vein endothelial cells; HMGB1, high-mobility group box protein 1; siRNA, small interfering RNA; GAPDH, glyceraldehyde 3-phosphate dehydrogenase.

A

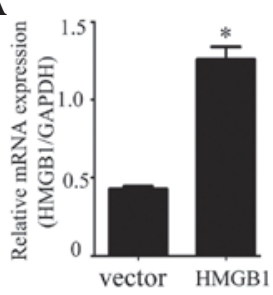

B

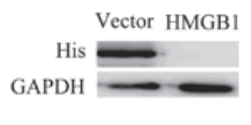

C

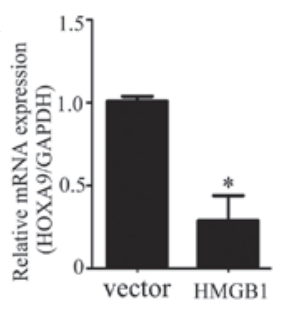

D

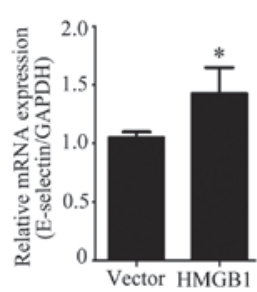

Figure 4. HMGB1 overexpression reduces the expression of HOXA9 and increases the expression of E-selectin in HUVECs. HUVECs were transfected with pcDNA-3.1-myc-his B-HMGB1 or pcDNA-3.1-myc-his B vector control. The expression of HMGB1 in HUVECs was detected by (A) RT-PCR and (B) western blot analysis. (C) The expression of HOXA9 was reduced, while (D) the expression of E-selectin was increased. Values are the means \pm SD of three independent experiments, each performed in triplicate. "P<0.05 vs. the vector control. HOXA9, homeobox A9; HUVECs, human umbilical vein endothelial cells; HMGB1, high-mobility group box protein 1; GAPDH, glyceraldehyde 3-phosphate dehydrogenase.

with the non-silencing siRNA control, both at the mRNA (Fig. 3A) and protein (Fig. 3B) levels; HOXA9 expression increased in HUVECs in which HMGB1 expression was silenced (Fig. 3C). Co-transfection with HMGB1 siRNA and HOXA9 siRNA significantly increased E-selectin levels in HUVECs compared with those in HMGB1 siRNA-transfected and control cells (Fig. 3D).
Effect of HMGB1 overexpression on E-selectin expression. To further confirm the effect of HMGB1 on E-selectin expression and to investigate the potential underlying mechanism, the fulllength HMGB1 gene was amplified by PCR according to the sequence in GenBank and was subcloned into pcDNA-3.1-mychis-B vector. Then, HUVECs were transfected with pcDNA-3.1-myc-his-B-HMGB1, using the pcDNA-3.1-myc- 
his-B vector as a control. Expression of HMGB1 in HUVECs was detected by RT-PCR and western blot analysis. The results showed expression of HMGB1 in the HUVECs was successfully achieved with the pcDNA-3.1-myc-his-B-HMGB1 vector at the mRNA (Fig. 4A) and protein (Fig. 4B) levels. RT-PCR showed that overexpression of HMGB1 in HUVECs increased the expression of E-selectin (Fig. 4C) and reduced the expression of HOXA9 (Fig. 4D).

\section{Discussion}

Sepsis, a lethal condition following infection or injury, is associated with a high mortality rate and afflicted 750,000 patients in the United States in 1995 (8). Pro-inflammatory cytokines lead to the development of tissue damage, metabolic acidosis, hypotension, MOF and even death (26). Two of these cytokines, TNF- $\alpha$ and interleukin (IL)-1 $\beta$, reached toxic levels in serum from mice and human volunteers within 1 to $2 \mathrm{~h}$ of LPS administration $(27,28)$. Thus, it is not surprising that delayed treatment therapies directed against early pro-inflammatory mediators have been ineffective in large clinical trials (28-32).

HMGB1 has been demonstrated to be a late mediator of lethal systemic inflammation in murine models and to be involved in delayed endotoxin lethality and systemic inflammation. Thus, as a pro-inflammatory cytokine, HMGB1 has been hypothesized to be an ideal target in sepsis therapy. Previous studies have provided evidence that therapy with anti-HMGB1 antibodies conferred significant protection against lethality, even when the first dose of antibody was administered $24 \mathrm{~h}$ after LPS administration. The endothelium plays an important role in the development of sepsis; the nucleus of the endothelial cell contains large amounts of HMGB1, and a number of studies have demonstrated that the endothelium may be a critical source of HMGB1 during inflammation (33).

In the present study, we used HUVECs as an in vitro model system and described the potential use of a plasmid-based shRNA targeting HMGB1 expression in endothelial cells. Results from the present study showed that HMGB1 is expressed in HUVECs, which is in agreement with a previous study on the expression of HMGB1 in endothelial cells (11). Some experimental approaches have been reported to result in inhibition of HMGB1 function in sepsis (29,34-37). Of these, antibodies are difficult to administer and may produce antigen-antibody complexes that stimulate the inflammatory response by further activating innate immune pathways, thus promoting further tissue damage. Antibody-based blockade strategies have shown limited efficacy in clinical trials against sepsis (38). Future studies are required in order to develop novel and selective antagonists for HMGB1 $(39,40)$.

In the present study, we proposed that downregulation of HMGB1 expression in the endothelium by RNAi may decrease inflammatory activity. RNAi-based techniques for silencing specific genes, either as synthetic RNA oligonucleotides or as plasmid-encoded shRNAs, are widely used. We examined a similar approach whereby vectors expressing three different shRNAs were used to suppress HMGB1 expression in HUVECs.

The human HMGB1 gene is located on chromosome 13 (41), and six polymorphic loci throughout the gene locus have recently been identified (42). The structure of HMGB1 is highly conserved across eukaryotic species, with $99 \%$ amino acid homology between rodents and humans (43-45). However, despite its clinical importance, there is limited knowledge regarding the intracellular signaling pathways activated by HMGB1 in inflammation. To the best of our knowledge, the present study is the first to investigate the role of potential signaling pathways that control the function of intracellular HMGB1 in inflammation.

Several studies have shown an increase in the soluble form of E-selectin in healthy human volunteers receiving an injection of LPS (46) and in patients hospitalized for sepsis (47). Levels of E-selectin in the plasma are positively correlated with the severity of sepsis in patients, as evaluated by the Simplified Acute Physiology Score II or the number of organ failures (i.e., MOF) score (48). Increased levels of adhesion molecules in the plasma reflect an increase in the endothelial membrane expression of the proteins and may be directly related to activation or dysfunction of the endothelium (49). In the current study, we demonstrate that blocking the expression of HMGB1 reduces E-selectin mRNA expression. This is in agreement with the finding that HMGB1, and the B-box of HMGB1 (a DNA-binding element), activate HUVECs to upregulate adhesion molecules such as ICAM1, VCAM1 and E-selectin in a dose-dependent manner (50). HOXA9, besides binding to DNA, may associate with the crucial architectural factor high-mobility group AT-hook 1 [HMGI(Y)], which has been suggested to be a general cofactor in HOX-mediated transcriptional activation (51). Furthermore, high HOXA9 expression regulates endothelial cell activation by inhibiting the activity of nuclear factor $\kappa$-light-chain-enhancer of activated B cells $(\mathrm{NF}-\kappa \mathrm{B})$. In other words, downregulation of HOXA9 may be a prerequisite for endothelial cell activation $(52,53)$.

In conclusion, endothelial cells with reduced HMGB1 expression resulted in elevated HOXA9 expression, and consequently decreased E-selectin expression. Additionally, the inhibition of HOXA9 expression was found to lead to elevated E-selectin expression. Therefore, it was confirmed that intranuclear HMGB1 regulates E-selectin expression via HOXA9. Further studies are required to delineate the details of HOXA9 interaction and transcriptional control of E-selectin expression.

\section{Acknowledgements}

This work was supported by the National Natural Science Foundation of China (No. 30901438) and Shenyang science and technology plan projects (No. 130309).

\section{References}

1. Skoko D, Wong B, Johnson RC and Marko JF: Micromechanical analysis of the binding of DNA-bending proteins HMGB1, NHP6A, and HU reveals their ability to form highly stable DNA-protein complexes. Biochemistry 43: 13867-13874, 2004.

2. Pallier C, Scaffidi P, Chopineau-Proust S, et al: Association of chromatin proteins high mobility group box (HMGB) 1 and HMGB2 with mitotic chromosomes. Mol Biol Cell 14: 3414-3426, 2003.

3. Yuan F, Gu L, Guo S, Wang C and Li GM: Evidence for involvement of HMGB1 protein in human DNA mismatch repair. J Biol Chem 279: 20935-20940, 2004.

4. Andersson U, Wang H, Palmblad K, et al: High mobility group 1 protein (HMG-1) stimulates proinflammatory cytokine synthesis in human monocytes. J Exp Med 192: 565-570, 2000. 
5. Fiuza C, Bustin M, Talwar S, et al: Inflammation-promoting activity of HMGB1 on human microvascular endothelial cells. Blood 101: 2652-2660, 2003.

6. Wang H, Bloom O, Zhang M, et al: HMG-1 as a late mediator of endotoxin lethality in mice. Science 285: 248-251, 1999.

7. Wang H, Yang H and Tracey KJ: Extracellular role of HMGB1 in inflammation and sepsis. J Intern Med 255: 320-331, 2004.

8. Angus DC, Linde-Zwirble WT, Lidicker J, Clermont G, Carcillo J and Pinsky MR: Epidemiology of severe sepsis in the United States: analysis of incidence, outcome, and associated costs of care. Crit Care Med 29: 1303-1310, 2001.

9. Lehr HA, Bittinger F and Kirkpatrick CJ: Microcirculatory dysfunction in sepsis: a pathogenetic basis for therapy? J Patho 190: 373-386, 2000.

10. Bae JS and Rezaie AR: Activated protein C inhibits high mobility group box 1 signaling in endothelial cells. Blood 118: 3952-3959, 2011.

11. Mullins GE, Sunden-Cullberg J, Johansson AS, et al: Activation of human umbilical vein endothelial cells leads to relocation and release of high-mobility group box chromosomal protein 1. Scand J Immunol 60: 566-573, 2004.

12. Yang H, Ochani M, Li J, et al: Reversing established sepsis with antagonists of endogenous high-mobility group box 1 . Proc Natl Acad Sci USA 101: 296-301, 2004

13. Qin S, Wang H, Yuan R, et al: Role of HMGB1 in apoptosismediated sepsis lethality. J Exp Med 203: 1637-1642, 2006.

14. Paul CP, Good PD, Winer I and Engelke DR: Effective expression of small interfering RNA in human cells. Nat Biotechnol 20: 505-508, 2002

15. Paddison PJ, Caudy AA, Bernstein E, Hannon GJ and Conklin DS Short hairpin RNAs (shRNAs) induce sequence-specific silencing in mammalian cells. Genes Dev 16: 948-958, 2002.

16. Kuniyasu H, Chihara Y and Kondo H: Differential effects between amphoterin and advanced glycation end products on colon cancer cells. Int J Cancer 104: 722-727, 2003.

17. Shapiro NI, Yano K, Sorasaki M, Fischer C, Shih SC and Aird WC: Skin biopsies demonstrate site-specific endothelial activation in mouse models of sepsis. J Vasc Res 46: 495-502, 2009.

18. Nooteboom A, van der Linden CJ and Hendriks T: Modulation of adhesion molecule expression on endothelial cells after induction by lipopolysaccharide-stimulated whole blood. Scand J Immunol 59: 440-448, 2004.

19. Sessler CN, Windsor AC, Schwartz M, et al: Circulating ICAM-1 is increased in septic shock. Am J Respir Crit Care Med 151: $1420-1427,1995$.

20. Bandyopadhyay S,AshrafMZ, Daher P, Howe PH and DiCorleto PE: HOXA9 participates in the transcriptional activation of E-selectin in endothelial cells. Mol Cell Biol 27: 4207-4216, 2007.

21. Trivedi CM, Patel RC and Patel CV: Differential regulation of HOXA9 expression by nuclear factor kappa B (NF-kappaB) and HOXA9. Gene 408: 187-195, 2008.

22. Weissberg PL and Bennett MR: Atherosclerosis - an inflammatory disease. N Engl J Med 340: 1928-1929, 1999.

23. Chen JW, Chen YH, Lin FY, Chen YL and Lin SJ: Ginkgo biloba extract inhibits tumor necrosis factor-alpha-induced reactive oxygen species generation, transcription factor activation, and cell adhesion molecule expression in human aortic endothelia cells. Arterioscler Thromb Vasc Biol 23: 1559-1566, 2003.

24. Patel CV, Sharangpani R, Bandyopadhyay S and DiCorleto PE: Endothelial cells express a novel, tumor necrosis factor-alpharegulated variant of HOXA9. J Biol Chem 274: 1415-1422, 1999.

25. Ross R: The pathogenesis of atherosclerosis: a perspective for the 1990s. Nature 362: 801-809, 1993

26. Tracey KJ, Beutler B, Lowry SF, et al: Shock and tissue injury induced by recombinant human cachectin. Science 234: 470-474, 1986.

27. Hesse DG, Tracey KJ, Fong Y, et al: Cytokine appearance in human endotoxemia and primate bacteremia. Surg Gynecol Obstet 166: 147-153, 1988.

28. Beutler BA, Milsark IW and Cerami A: Cachectin/tumor necrosis factor: production, distribution, and metabolic fate in vivo. J Immunol 135: 3972-3977, 1985.

29. Fink MP: Another negative clinical trial of a new agent for the treatment of sepsis: rethinking the process of developing adjuvant treatments for serious infections. Crit Care Med 23: 989-991, 1995.

30. Fisher CJ Jr, Dhainaut JF, Opal SM, et al; Phase III rhIL-1ra Sepsis Syndrome Study Group: Recombinant human interleukin 1 receptor antagonist in the treatment of patients with sepsis syndrome. Results from a randomized, double-blind, placebo-controlled trial. JAMA 271: 1836-1843, 1994.
31. Eskandari MK, Bolgos G, Miller C, Nguyen DT, DeForge LE and Remick DG: Anti-tumor necrosis factor antibody therapy fails to prevent lethality after cecal ligation and puncture or endotoxemia. J Immunol 148: 2724-2730, 1992

32. Remick D, Manohar P, Bolgos G, Rodriguez J, Moldawer L and Wollenberg G: Blockade of tumor necrosis factor reduces lipopolysaccharide lethality, but not the lethality of cecal ligation and puncture. Shock 4: 89-95, 1995.

33. Luan ZG, Zhang H, Yang PT, Ma XC, Zhang C and Guo RX: HMGB1 activates nuclear factor- $\kappa \mathrm{B}$ signaling by RAGE and increases the production of TNF- $\alpha$ in human umbilical vein endothelial cells. Immunobiology 215: 956-962, 2010.

34. Unoshima M: Therapeutic effect of anti-HMGB1 antibody and anti-RAGE antibody on SIRS/sepsis. Nihon Rinsho 62: 2323-2329, 2004 (In Japanese).

35. Parrish W and Ulloa L: High-mobility group box-1 isoforms as potential therapeutic targets in sepsis. Methods Mol Biol 361: 145-162, 2007.

36. Eriksson M: Should high mobility group box-1 protein (HMGB1) be measured in patients with severe sepsis and septic shock? If so, when, where, and how? Crit Care Med 33: 682-683, 2005.

37. Ulloa L, Ochani M, Yang $\mathrm{H}$, et al: Ethyl pyruvate prevents lethality in mice with established lethal sepsis and systemic inflammation. Proc Natl Acad Sci USA 99: 12351-12356, 2002.

38. Guo RF and Ward PA: Role of C5a in inflammatory responses. Annu Rev Immunol 23: 821-852, 2005.

39. Mantell LL, Parrish WR and Ulloa L: HMGB-1 as a therapeutic target for infectious and inflammatory disorders. Shock 25: 4-11, 2006.

40. Ulloa L and Messmer D: High-mobility group box 1 (HMGB1) protein: friend and foe. Cytokine Growth Factor Rev 17: 189-201, 2006.

41. Ferrari S, Finelli P, Rocchi M and Bianchi ME: The active gene that encodes human high mobility group 1 protein (HMG1) contains introns and maps to chromosome 13. Genomics 35: 367-371, 1996.

42. Kornblit B, Munthe-Fog L, Petersen SL, Madsen HO, Vindelov L and Garred P: The genetic variation of the human HMGB1 gene. Tissue Antigens 70: 151-156, 2007

43. Bustin M and Reeves R: High-mobility-group chromosomal proteins: architectural components that facilitate chromatin function. Prog Nucleic Acid Res Mol Biol 54: 35-100, 1996.

44. Ferrari S, Ronfani L, Calogero S and Bianchi ME: The mouse gene coding for high mobility group 1 protein (HMG1). J Biol Chem 269: 28803-28808, 1994.

45. Hardman CH, Broadhurst RW, Raine AR, Grasser KD, Thomas JO and Laue ED: Structure of the A-domain of HMG1 and its interaction with DNA as studied by heteronuclear three- and four-dimensional NMR spectroscopy. Biochemistry 34: 16596-16607, 1995.

46. Kuhns DB, Alvord WG and Gallin JI: Increased circulating cytokines, cytokine antagonists, and E-selectin after intravenous administration of endotoxin in humans. J Infect Dis 171: 145-152, 1995.

47. Boldt J, Muller M, Kuhn D, Linke LC and Hempelmann G: Circulating adhesion molecules in the critically ill: a comparison between trauma and sepsis patients. Intensive Care Med 22: $122-128,1996$

48. Kayal S, Jais JP, Aguini N, Chaudiere J and Labrousse J: Elevated circulating E-selectin, intercellular adhesion molecule 1, and von Willebrand factor in patients with severe infection. Am J Respir Crit Care Med 157: 776-784, 1998

49. Harlan JM and Winn RK: Leukocyte-endothelial interactions: clinical trials of anti-adhesion therapy. Crit Care Med 30: S214-S219, 2002

50. Treutiger CJ, Mullins GE, Johansson AS, et al: High mobility group $1 \mathrm{~B}$-box mediates activation of human endothelium. J Intern Med 254: 375-385, 2003.

51. Zappavigna V, Falciola L, Helmer-Citterich M, Mavilio F and Bianchi ME: HMG1 interacts with HOX proteins and enhances their DNA binding and transcriptional activation. EMBO J 15: 4981-4991, 1996.

52. Mark M, Rijli FM and Chambon P: Homeobox genes in embryogenesis and pathogenesis. Pediatr Res 42: 421-429, 1997.

53. Trivedi CM, Patel RC and Patel CV: Homeobox gene HOXA9 inhibits nuclear factor-kappa $\mathrm{B}$ dependent activation of endothelium. Atherosclerosis 195: 50-60, 2007. 